\title{
O Impacto da Espiritualidade no Trabalho Sobre o Bem-Estar Laboral
}

Impact of Workplace Spirituality on Well Being at Work

El Impacto de la Espiritualidad en el Trabajo Sobre el Bienestar Laboral

\section{André Luis Amorim Silva Filho} \& Maria Cristina Ferreira Universidade Salgado de Oliveira (UNIVERSO)

http://dx.doi.org/10.1590/1982-3703002482013

(cc) BY 
Resumo: A presente pesquisa objetivou investigar o poder preditivo da espiritualidade no trabalho sobre o bem-estar laboral. A amostra foi composta por 344 trabalhadores, de ambos os sexos, pertencentes a organizações públicas e privadas situadas predominantemente no estado do Rio de Janeiro. Esses indivíduos responderam a uma Escala de Espiritualidade no Trabalho, a uma Escala de Comprometimento Organizacional Afetivo, a uma Escala de Satisfação Geral no Trabalho e a uma Escala de Afetos Positivos no Trabalho. As análises de regressão múltipla evidenciaram que as dimensões da espiritualidade no trabalho associadas ao sentido do trabalho e ao sentimento de comunidade no trabalho predisseram positiva e significativamente a satisfação no trabalho, o comprometimento organizacional afetivo e os afetos positivos dirigidos ao trabalho. Tais resultados permitiram a conclusão de que, quando as necessidades espirituais dos membros da organização são satisfeitas, eles desenvolvem maior ligação afetiva com a organização.

Palavras-chave: Espiritualidade. Trabalho. Saúde. Psicologia.

Abstract: The present study aims at researching the predictive power of workplace spirituality on ones well being at work. The sample consisted of 344 employees, of both sexes, belonging to public and private organizations located predominantly in Rio de Janeiro state. These individuals responded to a workplace spirituality scale, an affective organizational commitment scale, a general satisfaction at work scale, and a positive affect at work scale. The multiple regression analysis showed that the spirituality dimensions related to meaning at work and sense of community at work positively and significantly predicted job satisfaction, i.e., affective organizational commitment and positive affect toward to work. These results allowed for the conclusion that when the spiritual needs of the members of the organization are met, they develop a greater emotional attachment to the organization.

Keywords: Spirituality. Work. Health. Psychology.

Resumen: El presente estudio tuvo como objetivo investigar la capacidad de predicción de la espiritualidad en el trabajo sobre el bienestar laboral. La muestra estuvo conformada por 344 empleados, de ambos sexos, pertenecientes a organizaciones públicas y privadas ubicadas principalmente en el estado de Rio de Janeiro. Estas personas respondieron a una Escala de Espiritualidad en el Trabajo, una Escala de Compromiso Organizacional Afectivo, una Escala de Satisfacción General en el Trabajo y una Escala de Afectos Positivos en el Trabajo. El análisis de regresión múltiple mostró que las dimensiones de la espiritualidad relacionadas con el sentido del trabajo y al sentimiento de comunidad en el trabajo predicen positiva y significativamente la satisfacción laboral, el compromiso organizacional afectivo y el afecto positivo dirigido al trabajo. Estos resultados llevaron a la conclusión de que cuando se satisfacen las necesidades espirituales de los miembros de la organización, ellos desarrollan una mayor vinculación emocional con la organización.

Palabras clave: Espiritualidad. Trabajo. Salud. Psicología. 


\section{Introdução}

Ao longo de todo o século XX, a Psicologia focou seus estudos, prioritariamente, nos aspectos negativos da vida. Apesar de a busca pelas causas destes fenômenos ter trazido significativa contribuição para a compreensão do ser humano e dos fatores que o afligiam, o foco das investigações psicológicas recaía muito mais na doença que na saúde (Snyder \& Lopez, 2009). Ao final da década de 1990, porém, surgiu um novo campo de pesquisa na ciência psicológica, denominado Psicologia Positiva, que levou os estudiosos a se deterem também na realização de pesquisas direcionadas aos aspectos positivos da vida humana (Seligman \& Csikszentmihalyi, 2000).

Acompanhando essa tendência, as investigações na área da Psicologia das Organizações e do Trabalho, que antes se voltavam, sobretudo, à análise dos malefícios físicos e psicológicos à saúde do trabalhador, também foram redirecionadas. Assim é que, na esteira do movimento denominado de abordagem do comportamento organizacional positivo (Youssef \& Luthans, 2007), fenômenos como o bem-estar laboral, por exemplo, passaram a ocupar cada vez mais a atenção dos pesquisadores organizacionais interessados em aprofundar o conhecimento acerca de suas dimensões, antecedentes e consequentes.

No que tange aos antecedentes desse construto, já existe atualmente disponível uma extensa literatura acerca dos fatores organizacionais e da tarefa que concorrem para a manifestação do bem-estar no trabalho (Warr, 2005; 2007). Contudo, apenas mais recentemente, os pesquisadores vêm se debruçando sobre os antecedentes individuais do referido fenômeno. A esse respeito, vale destacar a espiritualidade no trabalho, ou seja, a percepção de como a vida interior dos trabalhadores é viabilizada pelo contexto laboral e, ao mesmo tempo, exerce influência sobre ele, propiciando um trabalho que é significativo para o indivíduo e seus colegas de trabalho (Ashmos \& Duchon, 2000).

$\mathrm{Na}$ literatura estrangeira, diversos estudos empíricos (Clark et al., 2007; Milliman,
Czaplewski, \& Ferguson, 2003; Pawar, 2009; Perrone, Webb, Wright, Jackson, \& Ksiazak, 2006; Rego, Cunha, \& Souto, 2007a; Robert, Young, \& Kelly, 2006) têm demonstrado que a espiritualidade no trabalho constitui-se em um preditor positivo do bem-estar. No entanto, a abordagem dessas relações na literatura brasileira ainda é incipiente, conforme levantamento realizado nas bases de dados Scielo e Pepsic, a partir do ano 2000. Justificam-se, assim, estudos adicionais que possam concorrer para a elucidação das influências da espiritualidade sobre o bem-estar laboral e contribuir, dessa forma, para a implementação de estratégias mais eficientes de promoção do bem-estar no contexto laboral. Fundamentando-se nessas considerações, o presente trabalho teve como objetivo geral investigar o impacto da espiritualidade no trabalho sobre o bem-estar laboral. Adicionalmente, pretendeu-se também elaborar e verificar as características psicométricas de um instrumento para avaliação da espiritualidade no trabalho.

\section{O bem-estar laboral}

Vários autores têm procurado conceituar o bem-estar laboral, em que pese o fato de a falta de consenso ainda prevalecer nessa área. Assim é que Paz (2004), por exemplo, entende o bem-estar laboral como "a satisfação de necessidades e a realização de desejos dos indivíduos ao desempenhar seu papel na organização" (p. 138), enquanto Van Horn, Taris, Schaufeli e Schreurs (2004) consideram o bem-estar no trabalho como o resultado da avaliação positiva de características variadas do contexto laboral.

Warr (2005), por sua vez, define tal construto como um conjunto de sentimentos positivos dirigidos a um contexto específico, qual seja o do trabalho, e Paschoal e Tamayo (2008) caracterizam-no como "a prevalência de emoções positivas no trabalho e a percepção do indivíduo de que, no seu trabalho, expressa e desenvolve seus potenciais/habilidades e avança no alcance de suas metas de vida" (p.1 6). Siqueira e Padovam (2008), por seu turno, afirmam que o bem-estar no trabalho é um construto psicológico integrado por 
vínculos afetivos positivos com o trabalho e com a organização. Com o apoio dessas definições, o presente trabalho concebeu o bem-estar laboral como uma percepção positiva do ambiente de trabalho, que se expressa em emoções, sentimentos e atitudes favoráveis a tal contexto.

Diferentes modelos vêm sendo desenvolvidos com o intuito de caracterizar as principais dimensões nas quais o bem-estar laboral se desdobra. De acordo com o modelo discutido por Paz (2004), há sete indicadores de bem-estar laboral, quais sejam: a valorização no trabalho, o reconhecimento pessoal, a autonomia, a expectativa de crescimento, o suporte ambiental, os recursos financeiros e $o$ orgulho. A valorização no trabalho consiste na percepção do quanto o trabalho é importante para o indivíduo, para a organização e para a sociedade, enquanto o reconhecimento pessoal diz respeito à percepção de ser valorizado pelo trabalho realizado. A autonomia associase à percepção de liberdade para trabalhar de acordo com as próprias convicções, e a expectativa de crescimento pode ser entendida como a percepção das possibilidades de aprimoramento pessoal e profissional. $\mathrm{O}$ suporte ambiental define-se pela percepção de dispor de apoio material, tecnológico e social para realizar as tarefas, enquanto os recursos financeiros caracterizam-se pela percepção de uma justa remuneração pelo trabalho realizado. Por fim, o orgulho consiste no sentimento de satisfação pessoal por fazer parte da organização.

Segundo Siqueira e Padovam (2008), o bem-estar no trabalho compreende três componentes: a satisfação no trabalho, o envolvimento com o trabalho e o comprometimento organizacional afetivo. A satisfação no trabalho envolve os vínculos afetivos associados ao relacionamento interpessoal com chefes e colegas de trabalho, à remuneração e promoções obtidas pelo trabalhador e às tarefas por ele realizadas. Já o envolvimento com o trabalho associa-se a experiências positivas de imersão em atividades laborais que apresentam desafios, ausência de pensamentos e sentimentos contraditórios, feedbacks claros e imediatos à execução de tais atividades e sensação de supressão ou diminuição temporal. O comprometimento organizacional afetivo, por fim, caracterizase por uma ligação positiva do empregado com o empregador, pela alta identificação do primeiro com os objetivos da organização e pela percepção do reconhecimento da ligação do indivíduo com a instituição em que trabalha.

Van Horn et al. (2004), por sua vez, propuseram um modelo de bem-estar laboral que abrange cinco dimensões: bem-estar afetivo, bem-estar profissional, bem-estar social, bem-estar cognitivo e bem-estar psicossomático. A dimensão afetiva do bem-estar no trabalho inclui os afetos positivos dirigidos ao trabalho (sentimentos e emoções), a ausência de exaustão emocional (sentimento de estar livre de fontes de sobrecarga emocional), a satisfação no trabalho (estado íntimo positivo decorrente de um trabalho realizado que se expressa afetiva e cognitivamente) e o comprometimento organizacional afetivo (identificação e envolvimento do trabalhador com a organização para a qual trabalha). Já a dimensão do bem-estar profissional engloba a autonomia, a aspiração e a competência profissional. Dessa forma, quando o profissional tem liberdade para agir de forma autônoma em seu ambiente de trabalho e desempenha suas tarefas de modo competente, ele costuma apresentar maior bem-estar profissional. O bem-estar social inclui duas subdimensões: a despersonalização, que se refere a uma atitude indiferente e negativa perante as pessoas com quem se trabalha e o grau de funcionamento do indivíduo em suas relações sociais no trabalho. O bem-estar cognitivo reflete o funcionamento cognitivo dos trabalhadores, estando associado à capacidade dos profissionais de adquirir novas informações e de se concentrar no trabalho. Finalmente, o bem-estar psicossomático relaciona-se à ausência de queixas de natureza psicossomática, tais como dores de cabeça, desconfortos estomacais e intestinais ou afecções similares.

De acordo com Warr $(2005 ; 2007)$, a estrutura do bem-estar no trabalho pode ser descrita por meio de três eixos: desprazer-prazer, 
ansiedade-conforto e depressão-entusiasmo (Figura 1). O primeiro reflete sentimentos globais que vão do desprazer ao prazer. Os dois outros eixos são formados a partir da combinação do primeiro eixo com a dimensão de excitação ou não excitação mental, definidas pela ativação (ou não ativação) mental somada à direção positiva ou negativa de dada experiência. Tal dimensão, por si só, não constitui um eixo, sendo usada apenas na definição do segundo e terceiro eixos. Nesse sentido, o segundo eixo traduz-se pela combinação de baixos níveis de prazer com altas taxas de excitação mental (ansiedade) ou de níveis elevados de prazer com baixas taxas de excitação (conforto). O terceiro eixo é representado por altos níveis de prazer com altos níveis de excitação mental (entusiasmo) ou por baixos níveis de prazer combinados a baixos níveis de excitação (depressão).

No que tange aos antecedentes do bem-estar no trabalho, Warr (2007) postula a existência de 12 características do ambiente de trabalho, dividindo-as em cinco fatores associados à natureza da tarefa e em sete fatores relacionados ao contexto da organização. Os aspectos associados à natureza da tarefa são: (1) a oportunidade para exercer controle sobre o meio, que diz respeito ao grau de controle ou autonomia que os empregados detêm sobre as tarefas da estrutura organizacional; (2) a oportunidade para usar as próprias habilidades, entendida como o manejo efetivo de situações particulares por meio de habilidades previamente adquiridas; (3) a existência de objetivos gerados externamente (carga de trabalho), isto é, a quantidade e a qualidade de demandas externas e sua relação com a saúde e o desempenho do trabalhador. Assim, por exemplo, tanto os problemas de família quanto grandes cargas de trabalho podem afetar o desempenho do trabalhador; (4) a variedade de tarefas, que se refere às variações na natureza e no local de trabalho, nas tarefas exercidas e nas habilidades requeridas que podem ser repetitivas e monótonas ou variadas e interessantes, e (5) a clareza ambiental, que se associa a quão claras são para o trabalhador tanto as expectativas decorrentes do ambiente de trabalho, quanto às questões que dizem respeito ao seu desempenho e ao seu comportamento.

Dentre os aspectos relacionados à organização propriamente dita encontram-se: (1) a oportunidade de desenvolver contatos interpessoais, que se relaciona ao grau em que o ambiente de trabalho propicia ao trabalhador o desenvolvimento e a manutenção de relações interpessoais; (2) a segurança física, que se caracteriza por ambientes que propiciam, aos trabalhadores, conforto, saúde e segurança e possuem equipamentos adequados (ergonômicos); (3) as remunerações e recompensas, que se relacionam às percepções de justiça envolvidas no pagamento e nas recompensas recebidas, as quais podem acarretar emoções positivas (se estas são vistas como adequadas) ou negativas (quando percebidas como injustas); (4) a posição social valorizada, que diz respeito ao quanto o trabalhador se sente

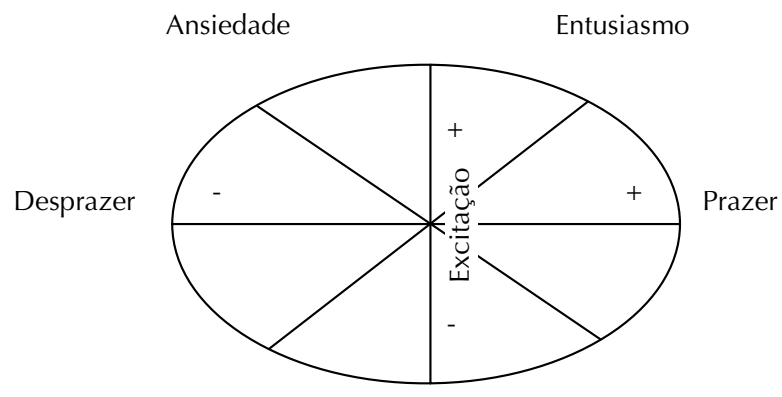

Depressão

Conforto

Figura 1. Os três eixos do bem-estar, segundo Warr (2005). 
valorizado ou desvalorizado em decorrência de sua profissão; (5) o suporte recebido da supervisão, que concerne ao suporte e consideração provenientes dos altos níveis gerenciais, envolvendo o estilo de liderança exercido sobre o empregado e o nível de acesso do trabalhador aos gerentes; (6) as perspectivas de carreira, que se referem à certeza ou incerteza do trabalhador sobre seu futuro na organização, e que podem Ihe causar insatisfação laboral, ansiedade e depressão, ou qualidade de vida e serenidade, a depender do que este percebe ou observa, e (7) a equidade, que diz respeito à presença de justiça e ausência de discriminação no ambiente de trabalho.

Em síntese, as diferentes conceituações e modelos desenvolvidos na tentativa de melhor compreender o bem-estar no trabalho evidenciam que, durante as últimas décadas, os esforços dos pesquisadores desse campo permitiram a compreensão mais acurada dos elementos que o compõem. Mesmo assim, porém, ainda não foi possível se chegar a um consenso sobre as diferentes dimensões que integram tal construto.

No entanto, a dimensão afetiva é a única comum aos diferentes modelos que vêm procurando caracterizar o bem-estar laboral, o que levou Van Horn et al. (2004) a classificá-la como a principal dimensão do bem-estar no trabalho. Ainda de acordo com esses autores, o bem-estar afetivo se desdobra em quatro dimensões: a satisfação no trabalho, o comprometimento organizacional afetivo, os afetos positivos dirigidos ao trabalho e a ausência de burnout. Fundamentando-se em tais considerações e nas manifestações de bem-estar afetivo propostas pelos vários autores já mencionados, a presente investigação optou por trabalhar com os seguintes indicadores afetivos do bem-estar no trabalho: comprometimento organizacional afetivo, satisfação no trabalho e afetos positivos dirigidos ao trabalho.

Cumpre registrar, ainda, que os modelos sobre o bem-estar laboral têm se preocupado basicamente com a descrição de suas dimensões ou componentes. Uma exceção a essa regra é o modelo de Warr (2007), que trata dos antecedentes do bem-estar no trabalho, mas se restringe à abordagem dos fatores da organização e da tarefa que nele interferem. Contudo, diferentes fatores individuais também se revestem da capacidade potencial de influenciar o bem-estar (Weinberg \& Cooper, 2007). Fundamentando-se nessas considerações, o presente trabalho aborda a relação do bem-estar no trabalho com uma característica individual, qual seja a espiritualidade no trabalho.

\section{A espiritualidade no trabalho}

Marques (2006) afirma que a espiritualidade no trabalho associa-se à consciência entre as pessoas, da necessidade de ligação, respeito e reconhecimento, o que faz com que ela não se restrinja aos ambientes privados, manifestando-se, ao contrário, principalmente nos ambientes profissionais. Ela se define, portanto, pelo sentido de conexão dos indivíduos à comunidade de trabalho; pela possibilidade de realizar tarefas com significado para as próprias vidas, desenvolvidas no contexto de uma comunidade; e pelo sentido de alegria e respeito pela vida interior, o que implica a necessidade de a organização fornecer oportunidades para que seus membros possam vivenciá-la (Rego et al., 2007a; Rego, Souto \& Cunha, 2007b).

Adotando perspectiva semelhante, Ashmos e Duchon (2000) enfatizam que a espiritualidade no trabalho se relaciona à percepção de como a vida interior dos trabalhadores é viabilizada pelo contexto laboral e, ao mesmo tempo, exerce influência sobre ele, propiciando um trabalho que é significativo para o indivíduo e seus colegas de trabalho. Em resumo, a espiritualidade não está ligada a um sistema religioso, nem a rituais organizados ou proselitismos, quando vivenciada no âmbito laboral, ou seja, ela não envolve doutrinas ou crenças religiosas institucionalizadas, estando, ao contrário, relacionada a uma nova perspectiva de humanização do trabalho, ao situá-lo em um contexto moral e social ampliado (Bell \& Taylor, 2004; Silva \& Siqueira, 2009). 
Diferentes autores têm proposto modelos sobre as dimensões compreendidas pelo construto em tela. Segundo Burack (1999), três pilares sustentam a espiritualidade no ambiente de trabalho: o interno, o externo e o integrado. $\mathrm{O}$ interno relaciona-se às qualidades inerentes ao trabalhador, como o respeito e a confiança. O externo diz respeito ao estabelecimento, pela organização, de alicerces éticos e ao gerenciamento dos méritos e valores das pessoas, assim como do desejo de criar climas de trabalho em que haja integridade. O último pilar integra os dois primeiros.

Moore e Casper (2006) também classificam a espiritualidade no ambiente de trabalho em três dimensões: autoimersão no trabaIho, interconectividade e autorrealização. A autoimersão no trabalho associa-se ao grau de apoio oferecido pela organização para que o funcionário vivencie aspectos de sua espiritualidade, no ambiente laboral. A interconectividade diz respeito ao sentimento de se sentir parte de algo muito maior que si mesmo, dentro da organização. A autorrealização, por fim, se relaciona à extensão em que os funcionários se sentem plenos ou realizados, ao vivenciarem experiências de crescimento mental e espiritual, por meio do trabalho.

O presente trabalho adotou, porém, a proposta de Ashmos e Duchon (2000) como referencial teórico na abordagem da espiritualidade no trabalho, em função de serem os trabalhos desses autores os que vêm sendo citados, mais frequentemente, na literatura da área organizacional (Milliman, et al., 2003; Pawar, 2009; Rego et al., 2007a; 2007b; Robert, et al., 2006). Segundo essa proposta, a espiritualidade no trabalho caracteriza-se por três vertentes: sentido do trabalho, sentimento de comunidade no trabalho e vida interior. O sentido do trabalho refere-se àquilo que vitaliza, anima e faz do trabaIho algo importante para o trabalhador. $\mathrm{O}$ sentimento de comunidade no trabalho, por sua vez, refere-se à percepção do local de trabalho como um lugar em que há espaço para o crescimento pessoal, a mútua valorização e o trabalho genuíno de equipe. A vida interior, por fim, compreende a consciência, por parte dos trabalhadores, de seus valores pessoais e do interesse para o que é espiritual.

\section{A espiritualidade no trabalho e o bem-estar laboral}

Diversos estudos vêm se dedicando à análise das relações entre a espiritualidade no trabalho e o bem-estar laboral. Atendo-se à dimensão do bem-estar associada à satisfação no trabalho, as evidências empíricas indicam que o sentimento de comunidade na equipe (Milliman et al., 2003), o trabalho significativo ou o significado do trabalho (Milliman et al., 2003; Pawar, 2009) e as crenças espirituais (Clark et al., 2007) se constituem em preditores positivos e significativos de tal variável. No que tange ao comprometimento organizacional, o senso de comunidade (Milliman et al., 2003; Pawar, 2009; Rego et al., 2007a) e o trabalho significativo ou significado do trabalho (Milliman et. al., 2003; Pawar, 2009) têm também se revelado preditores positivos e significativos dessa variável. Não foram, porém, encontrados estudos que correlacionassem a espiritualidade no trabalho com os afetos positivos dirigidos ao trabalho, nas bases de dados pesquisadas. Fundamentando-se, portanto, nos estudos empíricos mencionados e nas perspectivas teóricas de Ashmos e Duchon (2000) e de Van Horn et al. (2004), a presente pesquisa testou as seguintes hipóteses:

1. O sentido do trabalho prediz positivamente a satisfação no trabalho, o comprometimento organizacional afetivo e os afetos positivos dirigidos ao trabalho;

2. O sentimento de comunidade no trabalho prediz positivamente a satisfação no trabalho, o comprometimento organizacional afetivo e os afetos positivos dirigidos ao trabalho;

3. A vida interior prediz positivamente a satisfação no trabalho, o comprometimento organizacional afetivo e os afetos positivos dirigidos ao trabalho. 


\section{Método}

\section{Participantes}

Utilizou-se, no presente trabalho, um processo de amostragem por conveniência, tendo-se considerado como único critério de inclusão o fato de as pessoas estagiarem ou trabalharem há pelo menos um ano em qualquer tipo de organização. $\mathrm{O}$ número mínimo de participantes para atender aos pressupostos da análise de regressão múltipla deve ser, segundo Tabachnick e Fidell (2001), de $N \geq 50+8 n$ (sendo $n$ igual ao número de variáveis antecedentes), o que equivaleria a 122 participantes, ou, de acordo com Hair, Andersen, Tatham e Black (2005), igual a 50 vezes o número de variáveis independentes envolvidas no estudo, o que corresponderia, nesta pesquisa, a 150 participantes. No entanto, a amostra final foi composta por 344 trabalhadores, o que atendeu plenamente a ambos os critérios, apesar de nem todos terem respondido às questões sociodemográficas.

Os respondentes eram de ambos os sexos (58,9\% de mulheres), com idades variando de 18 a 67 anos (média = 32,97 anos; desvio padrão $=10,90$ ) e pertencentes a diferentes organizações públicas (40,4\%) e privadas $(59,6 \%)$, situadas no estado do Rio de Janeiro. No que tange à escolaridade, a maior parte da amostra $(92,8 \%)$ possuía nível superior incompleto ou completo. Quanto à função desempenhada, 24,8\% trabalhavam na área da saúde, 24,2\%, na área da educação e 11,7\%, na área de prestação de serviços, com o restante se subdividindo em funções variadas nas áreas de indústria, comércio, finanças, segurança pública e pesquisa. No que diz respeito à função desempenhada, 52,1\% do total de participantes encontravam-se no nível administrativo ou operacional. A média do tempo atual de trabalho foi de 5,5 anos (DP $=7,09$ ), enquanto a média do tempo total de trabalho foi de 12,9 anos (DP $=10,58)$. Os participantes que afirmaram possuir religião foram 82,5\%, sendo que $43,7 \%$ se declararam espíritas, $32,5 \%$, católicos e 12,6\%, protestantes.

\section{Instrumentos}

Para a avaliação da espiritualidade no trabalho, foi desenvolvida uma escala com o apoio do modelo teórico de Ashmos e Duchon (2000) e de instrumentos previamente validados para esse fim. Nesse sentido, as três dimensões propostas por estes autores, quais sejam a vida interior, o sentido do trabalho e o sentimento de comunidade, nortearam a construção do instrumento. Outrossim, os itens das escalas de Ashmos e Duchon (2000), de Milliman et al. (2003) e de Rego et al. (2007a) que se adequavam a uma dessas três dimensões, foram adaptados para o idioma português do Brasil. A versão inicial da escala de espiritualidade no trabalho (EET) ficou, portanto, composta por 39 itens, distribuídos conceitualmente nas três dimensões mencionadas, da seguinte forma: sentimento de comunidade no trabalho (15 itens), sentido do trabalho (15 itens) e vida interior (nove itens).

Em seguida, a EET foi submetida a uma análise de juízes. Para tanto, seus itens foram numerados de 1 a 39 e dispostos, de forma aleatória, em uma tabela apresentada a três psicólogas e três estagiárias de Psicologia. Elas receberam as definições de Ashmos e Duchon (2000) para os fatores selecionados e foram instruídas a eleger em qual dimensão cada item deveria permanecer e qual o seu grau de pertinência àquele fator, numa escala de 1 (pouco pertinente) a 5 (muito pertinente). Para a seleção dos itens resultantes dessa análise, foi adotado o critério de um mínimo de 60\% de concordância entre os juízes, acerca da dimensão selecionada e do grau de pertinência do item ao fator. Seis itens obtiveram $100 \%$ de concordância, 14 itens obtiveram $80 \%$ de concordância e apenas nove dos 14 restantes apresentaram pertinência e concordância suficientes para permanecer no instrumento. Dessa forma, a segunda versão da escala ficou com 29 itens, assim distribuídos: sentimento de comunidade (dez itens), sentido do trabalho (dez itens) e vida interior (nove itens).

Com a finalidade de averiguar se os itens propostos e as instruções apresentadas eram compreensíveis, outro grupo de quatro 
alunos de graduação e de pós-graduação em Psicologia efetuou a validação semântica do instrumento, apontando dificuldades de entendimento das frases, ambiguidades no vocabulário e termos complexos, tendo daí resultado a primeira versão experimental da EET, composta por 27 itens, a serem respondidos em escalas de cinco pontos, variando de discordo fortemente (1) a concordo fortemente (5), em função do grau de concordância do indivíduo com cada um deles. Tal versão foi a utilizada na coleta de dados do estudo, o que implicou a necessidade de busca de evidências iniciais acerca de sua validade, antes que os resultados nela obtidos pudessem ser utilizados no teste das hipóteses da pesquisa.

A satisfação no trabalho foi avaliada pela Escala de Satisfação Geral no Trabalho, construída e validada por Silva e Ferreira (2009), que é de natureza unifatorial e composta por cinco itens, a serem respondidos em escalas de cinco pontos, variando de concordo fortemente (5) a discordo fortemente (1). Assim, quanto maior o resultado, maior o grau de satisfação geral no trabalho. O alfa de Cronbach da escala na presente amostra foi igual a 0,90 .

O comprometimento organizacional afetivo no trabalho foi avaliado pela Escala de Comprometimento Afetivo de Meyer e Allen (1991), validada em amostras brasileiras por Ferreira et al. (2002). A escala também é unifatorial, sendo composta por seis itens, a serem respondidos em escalas de cinco pontos, variando de discordo totalmente (1) a concordo totalmente (5). Na presente amostra, a escala apresentou um alfa de Cronbach igual a 0,84 .

Os afetos positivos dirigidos ao trabalho foram avaliados pela versão reduzida da subescala de Afetos Positivos, pertencente à Escala de Afetos no Trabalho (ESAFE), de autoria de Ferreira, Silva, Fernandes e Almeida (2008). A escala é unifatorial e contém 10 itens, a serem respondidos em escalas de cinco pontos, variando de nunca (1) a sempre (5). $\mathrm{O}$ alfa de Cronbach da escala na presente amostra foi igual a 0,89 . O instrumento de coleta de dados contou, ainda, com um questionário sociodemográfico e com o termo de consentimento livre e esclarecido.

\section{Procedimentos}

Procedeu-se à administração do instrumento em versão eletrônica ou em lápis e papel, de forma coletiva ou individual. A aplicação coletiva ocorreu principalmente em estudantes universitários que estagiavam ou trabalhavam há pelo menos um ano, os quais foram contatados em suas respectivas salas de aula e responderam aos instrumentos na forma de lápis e papel. Já a aplicação individual envolveu trabalhadores de organizações públicas ou privadas, contatadas por meio da rede de amizades dos pesquisadores, que responderam sob a forma de lápis e papel, ou por meio eletrônico, com a utilização da ferramenta Goog/e Docs. Em ambas as situações, os participantes receberam inicialmente esclarecimentos acerca dos objetivos da pesquisa e o convite para dela participarem. Os que optaram voluntariamente por participar, assinaram o termo de consentimento livre e esclarecido e receberam as escalas que, após preenchidas, foram devolvidas. A todos os participantes foi assegurado o sigilo acerca das informações prestadas.

\section{Análise dos dados}

Para a análise dos dados, verificou-se inicialmente a validade fatorial da EET, mediante a realização de procedimentos de análise fatorial exploratória. Em seguida, foram calculadas as estatísticas descritivas (médias e desvios padrão) das diferentes escalas do estudo, bem como os coeficientes de correlação entre elas. Posteriormente, com o intuito de se verificar a possibilidade de a análise de regressão linear múltipla ser adotada na análise dos dados, foi necessário inspecionar se eles atendiam aos pressupostos desse tipo de análise (Tabachnick \& Fidell, 2001). Por fim, foram realizadas três análises de regressão múltipla linear, para se averiguar o poder preditivo das três dimensões da espiritualidade no trabalho sobre o comprometimento organizacional afetivo, a satisfação no trabalho e os afetos positivos dirigidos ao trabalho. 


\section{Resultados}

Validação fatorial da Escala de

Espiritualidade no Trabalho

No processo de validação da EET, foram inicialmente verificados os pressupostos da análise fatorial, por meio da medida de Kaiser Meyer Olkin (KMO), que apresentou resultado igual a 0,91, indicando, assim, a adequação dos dados à análise. Do mesmo modo, o teste de esfericidade de Bartlett foi significativo $\left(\chi^{2}=4682,75 ; p<0,001\right)$, numa evidência de que as correlações entre os itens permitiam a realização da análise fatorial.

Posteriormente, a matriz de intercorrelações entre os itens foi submetida à análise dos componentes principais, que extraiu cinco fatores com valores próprios (eingenvalues) maiores que 1, responsáveis por $63,25 \%$ da variância total do instrumento. De modo semelhante, o teste gráfico (screeplot) também revelou um número máximo de quatro a seis fatores interpretáveis.

Considerando-se, no entanto, que o modelo teórico original do instrumento previa a existência de três fatores, foi realizada, na sequência, uma análise fatorial por meio do método de eixos principais e rotação oblimin, com solução antecipada de três fatores. Tal solução mostrou-se totalmente interpretável e adequada à estrutura interna da escala. Esses três fatores foram responsáveis por 50,7\% da variância total do instrumento e neles, foram retidos os itens que apresentavam carga fatorial acima de 0,30 em apenas um fator e demonstravam, além disso, similaridade conceitual com os demais itens do fator. Posteriormente, optou-se, ainda, pela retirada de mais seis itens, de modo a que a versão final da escala contivesse igual número de itens em cada fator.

O primeiro fator obteve eigenvalue igual a 7,22 e ficou com sete itens associados ao sentido que o indivíduo atribui ao seu trabalho, ou seja, ao quão importante, significativo e energizante ele é (Ashmos \& Duchon, 2000). Por essa razão, ele foi denominado de sentido do trabalho (Tabela 1).
O eigenvalue do segundo fator foi de 4,83 e ele também ficou composto por sete itens relacionados ao sentimento de comunidade no trabalho, isto é, à percepção do local de trabalho como um espaço em que os indivíduos colaboram e dão suporte uns aos outros (Ashmos \& Duchon, 2000). Dessa forma, esse fator foi intitulado de sentimento de comunidade no trabalho (Tabela 1).

O terceiro e último fator ficou com eigenvalue igual a 1,60 e também se compôs de sete itens que se vinculam à vida interior, ou seja, à consciência do indivíduo sobre seus valores pessoais, ao valor que ele confere ao que é de natureza espiritual e à sua relação com o trabalho (Ashmos \& Duchon, 2000). Esse fator foi rotulado de vida interior (Tabela 1).

Em síntese, a versão final da EET ficou com 21 itens, distribuídos em três fatores: sentido do trabalho, sentimento de comunidade no trabalho e vida interior, cada um com sete itens. Quanto maior o escore em cada dimensão, maior o grau de espiritualidade por ela representado. Tais resultados se mostram, assim, consoantes com o modelo de Ashmos e Duchon (2000). Desta maneira, todas as análises posteriores para a comprovação das hipóteses utilizaram essa versão final da escala.

\section{Análises de regressão}

A Tabela 2 apresenta as médias, os desvios padrão e os coeficientes de correlação entre as variáveis do estudo. Com o intuito de verificar a possibilidade de a análise de regressão linear múltipla ser adotada na análise de dados, foi necessário inspecionar inicialmente se eles atendiam aos pressupostos de tal análise (Tabachnick \& Fidell, 2001). Tal análise indicou que os pressupostos de normalidade, linearidade e homocedasticidade, bem como a ausência de multicolinearidade e de outliers uni e multivariados, foram atendidos, razão pela qual não houve necessidade de transformação de nenhuma das variáveis do estudo.

Em seguida, foram então realizadas três análises de regressão múltipla linear, com 
o intuito de se verificar o poder preditivo dos fatores que compõem a espiritualidade no trabalho (sentido do trabalho, sentimento de comunidade no trabalho e vida interior) sobre cada um dos indicadores de bem-estar laboral incluídos no estudo (satisfação no trabalho, comprometimento organizacional afetivo e afetos positivos dirigidos ao trabalho).
A análise de regressão múltipla com a satisfação no trabalho como variável critério demonstrou que o conjunto das três variáveis preditoras que entrou na equação explicou $54 \%$ da variância de tal variável critério. No entanto, somente o sentido do trabalho e o sentimento de comunidade no trabalho se destacaram como preditores positivos e

Tabela 1. Cargas fatoriais dos itens da Escala de Espiritualidade no Trabalho.

\section{Itens}

24. Meu trabalho me faz crescer enquanto pessoa

26. Meu trabalho significa muito para mim

12. Realizo, em meu trabalho, coisas importantes para a minha vida

23. Sinto-me energizado com meu trabalho

1. Sinto prazer em trabalhar na maioria dos dias

5. Sinto-me feliz pelo fato de meu trabalho proporcionar felicidade a outras pessoas

8. Meu trabalho frequentemente me traz alegrias

16. No meu trabalho, as pessoas dão suporte umas às outras

27. No meu trabalho, as pessoas se preocupam genuinamente umas com as outras

3. No meu trabalho, as pessoas se sentem como fazendo parte de uma família

6. Trabalhar cooperativamente é algo valorizado em minha organização

10. Em meu trabalho, costumo resolver coletivamente os desafios que nos são colocados

19. Em meu trabalho, todos se encontram ligados por objetivos comuns

15. Quando tenho problemas pessoais, meus colegas de trabalho me encorajam a resolvê-los

13. Considero importante ter valores espirituais

7. A espiritualidade é parte importante da minha vida

17. Considero-me uma pessoa espiritualizada

20. Meus valores espirituais influenciam as escolhas que faço

9. Sinto necessidade de desenvolver minha espiritualidade

4. Tenho interesse por questões relacionadas à espiritualidade

21. Preocupo-me com minha vida interior
F1
0,78
0,76
0,75
0,73
0,60
0,60
0,60

F2

F3

0,88
0,79
0,77
0,65
0,58
0,51
0,50

0,89

0,89

0,88

0,85

0,84

0,76

0,62

Tabela 2. Médias, desvios padrão e coeficientes de correlação entre as dimensões da espiritualidade no trabalho e os indicadores do bem-estar laboral.

\begin{tabular}{lccccccc}
\hline Dimensões & M & DP & (1) & (2) & (3) & (4) & (5) \\
\hline Sentido do trabalho (1) & 3,76 & 0,80 & - & - & - & - & - \\
Vida interior (2) & 4,03 & 0,94 & 0,10 & - & - & - & - \\
Sentimento de comunidade no trabalho (3) & 3,38 & 0,82 & $0,53^{* *}$ & $-0,02$ & - & - & - \\
Afetos positivos dirigidos ao trabalho (4) & 3,62 & 0,66 & $0,72^{* *}$ & 0,01 & $0,45^{* *}$ & - & - \\
Satisfação no trabalho (5) & 3,29 & 1,06 & $0,72^{* *}$ & 0,02 & $0,53^{* *}$ & $0,63^{* *}$ & - \\
Comprometimento organizacional afetivo (6) & 3,48 & 0,95 & $0,61^{* *}$ & 0,02 & $0,55^{* *}$ & $0,56^{* *}$ & $0,65^{* *}$ \\
\hline
\end{tabular}

** $p<0,01$. 
significativos da satisfação no trabalho, com a primeira variável demonstrando maior poder preditivo que a segunda (Tabela 3 ).

Tomando-se o comprometimento organizacional afetivo como variável critério, foi observado que o conjunto das três variáveis que entraram na equação foram responsáveis por $43 \%$ da variância da variável critério. Contudo, apenas o sentido do trabalho e o sentimento de comunidade no trabalho se constituíram em preditores positivos e significativos da satisfação no trabalho (Tabela 3), com a primeira variável apresentando, novamente, maior poder preditivo que a segunda.

Na predição dos afetos positivos dirigidos ao trabalho, $53 \%$ da variância da variável critério foi explicada pelo conjunto das três variáveis que entraram na equação. Todavia, apenas as variáveis sentido do trabalho e sentimento de comunidade no trabalho (Tabela 3) destacaram-se como preditores positivos da variável critério.

\section{Discussão}

Foi objetivo geral do presente estudo investigar o poder preditivo de três dimensões da espiritualidade no trabalho (sentido do trabalho, vida interior e sentimento de comunidade no trabalho) sobre o bem-estar laboral, operacionalizado por meio da satisfação no trabalho, do comprometimento organizacional afetivo e dos afetos positivos dirigidos ao trabalho. Adicionalmente, elaborou-se um instrumento para avaliação da espiritualidade no trabalho e suas características psicométricas foram investigadas. Os dados obtidos demonstraram que o instrumento em questão apresentou estrutura fatorial congruente com o modelo que the serviu de base (Ashmos \& Duchon, 2000) bem como índices de consistência interna satisfatórios.

Os achados obtidos demonstraram, ainda, que dentre as três dimensões da espiritualidade no trabalho, o sentido do trabalho destacou-se como o principal preditor do bem-estar laboral. Verificou-se, assim, que as pessoas que consideram seu trabalho como importante, significativo e energizante, tendem também a demonstrar maiores vínculos afetivos com a organização, maior satisfação no trabalho e maior frequência de reações emocionais positivas dirigidas ao trabalho, o que confirmou integralmente a Hipótese 1 do estudo. Tais evidências se mostram, também, congruentes com os estudos de Milliman et al. (2003) e de Pawar (2009), que observaram a existência de uma associação positiva e significativa do sentido do trabalho com a satisfação no trabalho e com o comprometimento organizacional.

Foi constatado, ainda, que o sentimento de comunidade no trabalho também se constituiu em um preditor positivo e significativo do comprometimento organizacional afetivo, da satisfação no trabalho e dos afetos positivos dirigidos ao trabalho, o que confirmou integralmente a Hipótese 2 da investigação. Observou-se, assim, que os empregados que percebem seu local de trabalho como um espaço para o crescimento pessoal, a mútua

Tabela 3. Análise de regressão múltipla das três dimensões da espiritualidade no trabalho sobre os indicadores do bem-estar laboral.

\begin{tabular}{lccc}
\hline & \multicolumn{3}{c}{ Indicadores do bem-estar laboral } \\
\cline { 2 - 4 } & $\begin{array}{c}\text { Satisfação no } \\
\text { trabalho }(\beta)\end{array}$ & $\begin{array}{c}\text { Comprometimento } \\
\text { organizacional afetivo }(\beta)\end{array}$ & $\begin{array}{c}\text { Afetos positivos } \\
\text { dirigidos ao trabalho }(\beta)\end{array}$ \\
\hline Sentido do trabalho & $0,62 * * *$ & $0,45^{* * *}$ & $0,67 * * *$ \\
Vida interior & $-0,02$ & $-0,02$ & $-0,04$ \\
Sentimento de comunidade no trabalho & $0,19 * * *$ & $0,30 * * *$ & $0,10^{*}$ \\
$R^{2}$ Ajustado & 0,54 & 0,43 & 0,53 \\
$F$ & $120,60 * * *$ & $79,86^{* * *}$ & $112,52^{* * *}$ \\
\hline
\end{tabular}


valorização e o trabalho genuíno de equipe mostram-se mais comprometidos afetivamente com sua organização empregadora, além de sentirem-se mais satisfeitos e dirigirem mais afetos positivos a seu trabalho. Tais evidências fornecem, mais uma vez, sustentação empírica às formulações de Milliman et al. (2003) e de Pawar (2009), que encontraram evidências anteriores de que o sentimento de comunidade no trabalho prediz positiva e significativamente tanto o comprometimento organizacional afetivo quanto a satisfação com o trabalho.

Tomados em conjunto, esses resultados podem ser interpretados de acordo com as formulações de Ashmos e Duchon (2000), segundo as quais os seres humanos, além de racionais e emocionais, são também seres espirituais em busca do sentido e do significado do trabalho que desenvolvem em um contexto de comunidade. Consequentemente, quando as organizações proveem esses espaços, isto é, quando seus membros satisfazem essas necessidades, eles desenvolvem maior ligação afetiva com ela. Em outras palavras, quando as organizações se mostram capazes de satisfazer as necessidades espirituais relacionadas à segurança psicológica e emocional, ao senso de valorização, ao sentido de propósito, à autodeterminação e ao sentimento de pertencimento de seus membros, elas favorecem o desenvolvimento de maior ligação afetiva com a organização (Rego et al., 2007a). Em síntese, a espiritualidade no trabalho encontra-se associada às necessidades espirituais de natureza mais elevada dos indivíduos, razão pela qual ela induz a respostas afetivas mais favoráveis (Duchon \& Plowman, 2005; Pawar, 2009), conforme demonstrado na presente pesquisa.

Resta, contudo, discutir o motivo pelo qual a vida interior não se apresentou como preditora de nenhuma das dimensões do bem-estar laboral. Uma possível explicação pode estar relacionada ao fato de que os itens que compõem as dimensões da escala de espiritualidade no trabalho associadas ao sentido do trabalho e ao sentimento de comunidade no trabalho encontram-se mais vinculados ao contexto do trabalho em si, enquanto os itens da dimensão vida interior apresentam natureza mais relacionada ao indivíduo, independentemente de sua inserção em uma organização laboral. Considerando-se que todas as variáveis critério utilizadas tinham como referente o contexto do trabalho, é possível ser esta a razão pela qual apenas as dimensões da espiritualidade relativas ao contexto do trabalho afetaram as diferentes dimensões do bem-estar compreendidas pelo estudo.

\section{Considerações finais}

O presente estudo propôs-se a investigar o impacto da espiritualidade no trabalho sobre o bem-estar laboral, sendo que os resultados obtidos permitiram a conclusão de que quanto maior o sentido do trabalho e o sentimento de comunidade no trabalho, maiores os índices de satisfação no trabalho, de comprometimento organizacional afetivo e de afetos positivos dirigidos ao trabalho. Tais achados permitem a elaboração de algumas sugestões de estratégias que podem ser futuramente adotadas, com o objetivo de reforçar os níveis de bem-estar no trabalho.

Nesse sentido, sugere-se maior preocupação dos gestores quanto à implementação de atividades que fomentem o sentido do trabalho e o sentimento de comunidade no trabalho, entre os empregados. Considerando-se que as necessidades espirituais são satisfeitas por meio de determinados recursos existentes no ambiente laboral, seria interessante também que os gestores procurassem incluí-las em seu planejamento estratégico. Em outras palavras, a adoção de práticas organizacionais que levem em conta a espiritualidade de seus membros poderá se revelar útil à melhoria do bem-estar no trabalho.

Atendo-se a uma futura agenda de pesquisas, seria recomendável verificar que outros fatores da espiritualidade, associados ao indivíduo ou à organização, incidem sobre o bem-estar no trabalho. Outrossim, o fato de a dimensão da espiritualidade associada à vida interior não ter se correlacionado com as dimensões do bem-estar laboral compreendidas pelo estudo indica a necessidade de investigações 
ulteriores capazes de aprofundar as diferenças existentes entre ela e as demais dimensões da espiritualidade no trabalho.

Cumpre ressaltar, por fim, as limitações da presente pesquisa. O fato de ela ter se baseado em um desenho metodológico de natureza correlacional implica a impossibilidade de estabelecimento de relações causais entre os fenômenos investigados, na medida em que outros fatores não controlados podem ter concorrido para os efeitos observados. Outra limitação consiste no fato de ela ter sido conduzida apenas no estado do Rio de Janeiro, o que diminui suas possibilidades de generalização.

De todo modo, o presente trabalho reveste-se de importância prática e teórica, por ter apresentado evidências iniciais de validade sobre um novo instrumento para a medida da espiritualidade no trabalho e por contribuir para o avanço do conhecimento sobre os fatores individuais que concorrem para a promoção do bem-estar no contexto do trabalho. 
Referências
Ashmos, D. P., \& Duchon, D. (2000). Spirituality at work: a conceptualization and measure. Journal of Management Inquiry, 9(2), 134-145.

Bell, E., \& Taylor, S. (2004). A exaltação do trabalho: o poder pastoral e a ética do trabalho na nova era. Revista de Administração de Empresas, 44(2), 64-78.

Burack, E. H. (1999). Spirituality in the workplace. Journal of Organizational Change Management, 12(4), 280-291.

Clark, L., Leedy, S., McDonald, L., Muller, B., Lamb, C., Mendez, T., Kim, S., \& Schonwetter, R. (2007). Spirituality and job satisfaction among hospice interdisciplinary team members. Journal of Palliative Medicine, 10(6), 1321-1328.

Duchon, D., \& Plowman, D. A. (2005). Nurturing the spirit at work: impact on work unit performance. The Leadership Quarterly, 16(5), 807-833.

Ferreira, M. C., Assmar, E. M., Braga, L. L., Souto, S. O., Rocha, P. M., \& Lamastra, G. P. (2002). Adaptação brasileira de uma escala tridimensional para avaliação do comprometimento organizacional [Resumo]. In Conselho Federal de Psicologia (Ed..), Anais do I Congresso Brasileiro Psicologia: Ciência e Profissão. Brasília, DF: CFP. Recuperado de http://www.cienciaeprofissao.com.br/ congre/downloads.asp

Ferreira, M. C., Silva, A. P. C., Fernandes, H., \& Almeida, S. P. (2008). Desenvolvimento e validação de uma escala de afetos no trabalho (ESAFE). Avaliação Psicológica, 7(2), 143-150.

Hair, J. F., Andersen, R. E., Tatham, R. L. \& Black, W. C. (2005). Análise multivariada de dados. Porto Alegre: Artmed.

Marques, J. F. (2006). The spiritual worker: an examination of the ripple effect that enhances quality of life in-and outside the work environment Journal of Management Development, 25(9), 884-895.

Meyer, J. P., \& Allen, N. J. (1991). A threecomponent conceptualization of organizational commitment. Human Resources Management Review, 1(1), 61-89.
Milliman, J., Czaplewski, A. J., \& Ferguson, J. (2003). Workplace spirituality and employee work attitudes: An exploratory empirical assessment. Journal of Organizational Change Management, 16(4), 426-447.

Moore,T.W., \& Casper,W.J.(2006).Anexamination of proxy measures of workplace spirituality: A profile model of multidimensional constructs. Journal of Leadership and Organizational Studies, 12(4), 109-118.

Paschoal, T., \& Tamayo, A. (2008). Construção e validação da escala de bem-estar no trabalho. Avaliação Psicológica, 7(1), 11-22.

Pawar, B. S. (2009). Individual spirituality, workplace spirituality and work attitudes: an empirical test of direct and interaction effects. Leadership \& Organization Development Journal, 30(8), 759-777.

Paz,M.G.T.(2004). Poderesaúdeorganizacional. In A. Tamayo (Ed.), Cultura e saúde nas organizações (pp.127-154). Porto Alegre, RS: Artmed.

Perrone, K. M., Webb, L. K., Wright, S. L., Jackson, Z. V., \& Ksiazak, T. M. (2006). Relationship of spirituality to work and family roles and life satisfaction among gifted adults. Journal of Mental Health Counseling, 28, 253-268.

Rego, A., Cunha, M. P., \& Souto, S. (2007a). Espiritualidade nas organizações e comprometimento organizacional. Revista de Administração de Empresas, 6(2), 1-27.

Rego, A., Souto, S., \& Cunha, M. P. (2007b). Espiritualidade nas organizações, positividade edesempenho. Comportamento Organizacional e Gestão, 13(1), 7-36.

Robert T. E., Young J. S., \& Kelly, V. A. (2006). Relationships between adult workers' spiritual well-being and job satisfaction: a preliminary study. Counseling and Values, 50(3), 165-175.

Seligman, M. E. P., \& Csikszentmihalyi, M. (2000). Positive psychology: an introduction. American Psychologist, 55(1), 5-14.

Silva, A. P. C., \& Ferreira, M. C. (2009). Escala de satisfação geral no trabalho [Resumo]. In Instituto Brasileiro de Avaliação Psicológica (Ed.), Anais do IV Congresso Brasileiro de Avaliação Psicológica (p. 246). Campinas, SP: IBAP. 
Silva, R. R., \& Siqueira, D. (2009). Espiritualidade, religião e trabalho no contexto organizacional. Psicologia em Estudo, 14(3), 557-564.

Siqueira, M. M. M., \& Padovam, V. A. R. (2008). Bases teóricas do bem-estar subjetivo, bem-estar psicológico e bem-estar no trabalho. Psicologia: Teoria e Pesquisa, 24(2), 201-220.

Snyder, C. R., \& Lopez, S. J. (2009). Bom trabalho, a psicologia do trabalho gratificante. In C. R. Snyder, \& S. J. Lopez (Eds.), Psicologia positiva: uma abordagem científica e prática das qualidades humanas. (R. C. Costa, Trad.) (pp. 364-396). Porto Alegre, RS: Artmed.

Tabachnick, B. G., \& Fidell, L. (2001). Using multivariate statistics (4a ed.). Boston, MA: Allyn and Bacon.

Van Horn, J. E., Taris, T. W., Schaufeli, W. B., \& Schreurs, P.J.G. (2004). The structure of occupational well-being: a study among
Dutch teachers. Journal of Occupational and Organizational Psychology, 77(3), 365-375.

Warr, P. (2005). Work, well-being, and mental health. In E. K. Kelloway, \& M. R. Frone (Eds.), Handbook of work stress (pp. 547-573). London, UK: Sage Publications.

Warr, P. (2007). The vitamin analogy. In P. Warr (Eds.), Work, happiness and unhappiness (pp. 81-110). Vancouver, CA: Routledge.

Weinberg, A., \& Cooper, C. L. (2007). Models of emotional well-being at work. In A.Weinberg, \& C. L. Cooper (Eds.), Surviving the workplace: a guide to emotional well-being (pp. 55-69). London, UK: Thomson Learning.

Youssef, C. M., \& Luthans, F. (2007). Positive organizational behavior in the workplace: the impact of hope, optimism, and resilience. Journal of Management, 33(5), 774-800. 


\section{André Luis Amorim Silva Filho}

Mestree doutorando em Psicologia pela Universidade Salgado de Oliveira(UNIVERSO). Email: aamorimsilvafilho@yahoo.com.br

\section{Maria Cristina Ferreira}

Doutora em Psicologia pela Fundação Getúlio Vargas - RJ; Professora Titular do Programa de Pós-Graduação em Psicologia da Universidade Salgado de Oliveira (UNIVERSO). E-mail: mcris@centroin.com.br

\section{Endereço para envio de correspondência:}

Endereço: Rua Sá Viana, 107 apto. 403, Grajaú. CEP: 20540-260. Rio de Janeiro - RJ. Brasil.

Recebido: 19/11/2013, Aprovado: 14/09/2015. 